Check for updates

Cite this: RSC Adv., 2017, 7, 21869

Received 29th January 2017 Accepted 12th April 2017

DOI: 10.1039/c7ra01256j

rsc.li/rsc-advances

\section{A comparative study of the mechanical, shape- memory, and degradation properties of poly(lactic acid) nanofiber and cellulose nanocrystal reinforced poly(mannitol sebacate) nanocomposites $\dagger$}

\begin{abstract}
Águeda Sonseca, (iD *a Olivia Menes ${ }^{\mathrm{b}}$ and Enrique Giménez ${ }^{\mathrm{a}}$
Nanocomposites based on a poly(mannitol sebacate) (PMS) matrix - a member of the poly(polyol sebacate) (PPS) polyester family - reinforced either with cellulose nanocrystals (CNCs) or electrospun poly(lactic acid) nanofibers (NF-PLA) have been developed in order to evaluate the reinforcing filler morphology for achieving useful adaptive materials with shape-memory functionality. All the as-prepared nanocomposites have better mechanical properties than the neat PMS matrices, allowing for a wider range of mechanical and degradation properties. However, a superior balance of properties was observed after the introduction of PLA electrospun nanofibers into the low-modulus PMS matrix. In particular, enhanced shape-memory properties are imparted to the PMS matrix by using PLA nanofibers as reinforcing filler, specifically in a temperature range $\left(15-45^{\circ} \mathrm{C}\right)$ of interest for possible medical applications. In addition, two well-separated thermal glass transitions due to matrices and PLA nanofibers could enable the future design of triple-shape-memory systems. Mechanical properties are markedly enhanced with a 4 -fold increase when 4 wt\% of PLA nanofibers are infiltrated. On increasing the filler content to 10 and $15 \mathrm{wt} \%, 20$-fold and 53-fold enhancements in the Young's modulus were achieved, respectively. These better mechanical properties are accompanied by higher toughness than the neat matrix without reducing the elongation at break. In addition, the shape stability during degradation and the obtained mass loss rates imply that these nanocomposites are useful materials for long-term implants. Here we introduce a sequence of materials based on different fillers that offers great design flexibility, as depending on the geometry and amount of filler employed the properties of the obtained composites can be adjusted to those of living soft to hard tissues, being useful to configure biomedical devices with specific properties, such as for the treatment of patients with coronary artery disease.
\end{abstract}

\section{Introduction}

Soft biodegradable polyesters have been gaining attention as potentially useful polymers in the biomedical field due to the possibility off tuning their mechanical properties and degradation profiles by adjusting the processing conditions or the composition ratio. ${ }^{\mathbf{1 - 1 4}}$ Typically, all the reported systems are easily prepared through melt polycondensation reactions, and by using non-toxic monomers that incorporate ester bonds in the polymer chains, which allows hydrolytic degradation and enzymatic activity., ${ }^{\mathbf{1 1 5}} \mathrm{A}$ wide range of monomers have been

${ }^{a}$ Instituto de Tecnología de Materiales, Universitat Politècnica de València (UPV), Camino de Vera s/n, 46022 Valencia, Spain.E-mail: agsonol@posgrado.upv.es ${ }^{b}$ Instituto Tecnológico del Plástico (AIMPLAS), Parque Tecnológico, Calle Gustave Eiffel 4, 46980, Paterna, Valencia, Spain

$\dagger$ Electronic supplementary information (ESI) available. See DOI: 10.1039/c7ra01256j used for the synthesis of crosslinked polyester elastomers: nevertheless, the most common materials are based on the reaction of glycerol, 1,10-decanediol or low molecular weight poly(ethylene glycol) with either adipic acid, sebacic acid, 1,10decanedioic acid, 1,12-dodecanedioic acid or citric acid., ,4,16,17 $^{\mathbf{3}}$ Recently, poly(glycerol sebacate) (PGS), the most studied member of poly(polyol sebacate) (PPS) polyesters family, has been considered a good candidate for cardiovascular, cartilage and nerve tissue applications, among others. In order to enhance the range of potential biomedical and clinical applications, many efforts have been made in the development of other members of this family by polycondensation reactions of sebacic acid with other polyols such as mannitol, sorbitol, xylitol and maltitol. ${ }^{\mathbf{1 , 3 , 6 , 1 1 , 1 8 - 2 1}}$ Despite the wider range of Young's modulus ( $E$ 0.05-13 $\mathrm{MPa}$ ) and ultimate tensile strength (UTS 0.6-3.3 MPa) among the members of the PPS family and the elongation at break of greater than $10 \%$ (as required for tissue engineering), ${ }^{1}$ these materials have still not proven useful for 
many applications in which high strength and flexibility are required. For example, these materials have not been shown to work as ligating rubber bands for blood vessels or arteries, elastomeric sutures, flexible coatings for stents, surgical devices and wound dressings, vascular grafts, catheters or smalldiameter tubes for drainage and cartilage tissue engineering. ${ }^{22}$ That is, the current applications do not involve elastic and stiff tissues (E 0.7-250 MPa; UTS 0.3-54 MPa) such as skin, nerves, cartilage, heart valves, tendons and trabecular bones, among others. $^{23-26}$ In this instance, the most appropriated strategy involves nanocomposites materials designed to achieve a higher modulus without significantly lowering or compromising the elongation at break of the elastomeric matrix. Typically, this has been reported in the literature through the introduction of nanosized inorganic components in the matrices, such as halloysite nanotubes (clays), multi-walled carbon nanotubes (MWCNTs) and bioceramics. ${ }^{27-29}$ In this regard, we have previously reported ${ }^{30,31}$ that the addition of cellulose nanocrystals (CNCs) in poly(mannitol sebacate) (PMS) matrices results in efficient and highly compatible filler that is able to interact with the matrix both physically and chemically, ${ }^{32,33}$ positively affecting the systems properties. CNCs exhibit an impressive mechanical properties with a Young's modulus value about $130 \mathrm{GPa}$ making them interesting fillers for polymer composites. ${ }^{34}$ In this regard, we have demonstrated that the presence of CNCs in PMS matrices, combined with different crosslinking profiles (thermal curing under low- and high-temperature/time conditions) and stoichiometry between mannitol and sebacic acid $(1: 1$ and $1: 2)$, results in an improvement in mechanical properties well above that of the enhancement obtained by other fillers, without highly compromising the elongation at break of the neat matrices. In addition, this method provides more reliable mechanical support without an immediate loss of mechanical stability during immersion in simulated body fluid (SBF).

In addition, from a medical point of view, biodegradability and thermal-induced shape-memory properties at physiological temperature are both highly desirable for surgical implantation and minimally invasive applications. This combination is especially advantageous, as a device could be inserted in a smaller shape into the body to pass through narrow places, and once in its final position, be deployed to adopt its final functional shape; it can then be reabsorbed when its objective is fulfilled. ${ }^{35-39}$ To cover these needs for shape-memory polymers (SMPs) with biomedical applications, apart from achieving a thermal transition ( $T_{\text {trans }}$ ) close to the body's temperature, it is essential to improve the mechanical properties of polymers, including the strength and the rubbery modulus of the polymer networks, to avoid device failure when working in restricted environments (surrounded by tissues) inside the body. ${ }^{40}$ In this respect, to get SMPs with excellent shape-memory properties, particulate and layered nanofillers have typically been used to modify the thermal and mechanical properties of soft biodegradable matrices to ensure high strength and minimum flexibility and elasticity at implantation temperatures. Moreover, there has been steady progress in the development of new polymeric fibers processed by electrospinning, ${ }^{41}$ with nanometer architecture and unique features (high aspect ratio, flexibility and surface area along with light weight) to be used in a wide variety of applications including tissue engineering for wound healing and tissue regeneration, drug delivery, filtration devices and biosensors, among others. ${ }^{42,43}$ These facts imply that electrospun nanofibers are promising fillers ${ }^{44-46}$ to achieve high strength and long-term implantable shape-memory devices. Recent literature has included only a couple of stimuli-responsive polymer composites. These were fabricated with electrospun mats as fillers of non-degradable matrices, in which shape-memory was achieved through melting semicrystalline poly(E-caprolactone) (PCL) nanofibers at $60{ }^{\circ} \mathrm{C} \cdot{ }^{47,48}$ However, the use of PCL nanofiber mats as a switching phase has some drawbacks. The shape fixity depends on the PCL meltcrystallization process, and it is a time-consuming process due to the slow crystallization kinetics of this material. In addition, as the system works above $T_{\mathrm{m}}$ of the PCL, changes in the morphology due to partial melting of the nanofibers can take place. Therefore, with this background and the benefit of our previous experience in the development of PMS nanocomposites with potential applications in the biomedical field, here we report in this paper a new type of SMP based on the use of poly(lactic acid) (PLA) nanofibers obtained through the electrospinning process as a fixing phase in a PMS matrix, with 1: 2 mannitol : sebacic acid (MA : SA) ratio, to conform a glass transition temperature $\left(T_{\mathrm{g}}\right)$ based recovery. The enhanced mechanical stiffness of PLA nanofibers mats and their flexibility compared to that of bulk polymer are expected to provide an advantage over the individual polymer in terms of physical, mechanical and shape-memory properties, especially in the shape fixity ratio.

In this study, to complete our previous research about nanocomposites based on PMS (1:2 MA : SA ratio) reinforced with $\mathrm{CNCs}^{31}{ }^{31}$ we further evaluate the thermal induced shapememory properties of this system to provide a comparative study between poly(lactic acid) nanofibers and cellulose nanocrystals reinforced PMS matrices. This comparison, allowed us to better understand how different fillers affect matrix properties as well as to evaluate the usefulness of each kind of filler in developing nanocomposite materials as shape-memory polymers (SMPs). In summary, the main interest of the present work is to determine the mechanical and functional properties, through the use of nanofillers, of low modulus PMS (MA : SA $1: 2$ ratio). The addition of either CNCs or NF-PLA as reinforcing fillers in a poly(mannitol sebacate) (PMS) matrix, resulted in an effective approach to adapt the properties of the composite in terms of degradation time, mechanical properties and stability under simulated physiological conditions. These features allow to expand the range of possible applications within the medical field. By way of example, the developed CNCs nanocomposites can act as good mechanical support during wound healing and regeneration of elastic soft damaged tissues, while NF-PLA nanocomposites will be more compliant for tough tissues. Moreover, the presence of the NF-PLA could allow the encapsulation of drugs for control realising, as well as the customization of these materials for use in resorbable, minimally invasive and long-term and high-strength 
biomedical implantation shape-memory and hernia repair devices, among others.

\section{Experimental section}

\subsection{Materials}

Deuterated dimethylsulfoxide (DMSO- $d_{6}$ ), dichloromethane (DCM), N,N-dimethylformamide (DMF), sulfuric acid, sebacic acid (SA) (99\% purity), and D-mannitol (MA) (99\% purity), were purchased from Sigma Aldrich. Poly(lactic acid) (PLA) with 3\% of D-lactic acid monomer was supplied by NatureWorks ${ }^{\circledR}$ (USA) under the trade name PLA3051D $\left(M_{\mathrm{n}} c a .142 \times 10^{4} \mathrm{~g} \mathrm{~mol}^{-1}\right.$, density $\left.1.24 \mathrm{~g} \mathrm{~cm}^{-3}\right)$. Hydrochloric acid $(\mathrm{HCl}, 37 \%$ reagent grade) and sodium hydroxide ( $\mathrm{NaOH}, 98 \%$ reagent grade) were purchased from Scharlau. Ultrapure water was directly taken from a Sartorius Stedim Arium 611 VF® water purification system $(\rho=18.2 \mathrm{~m} \Omega \mathrm{cm})$. Cellulose nanocrystals (CNCs) were isolated from cotton (Whatman no. 1 filter paper) by controlled hydrolysis with sulphuric acid according to a protocol that is a modification of the method originally described by Dong et al. ${ }^{49}$ Briefly, the filter paper $(5 \mathrm{~g})$ was soaked in ultrapure water $(250 \mathrm{~mL}, \rho=18.2 \mathrm{~m} \Omega \mathrm{cm}$ ) and hydrolysed with sulphuric acid $(140 \mathrm{~mL})$ at $50{ }^{\circ} \mathrm{C}$ for $4 \mathrm{~h}$ under stirring. The CNCs were separated by centrifugation and dialyzed against ultrapure water until pH 5. The final dispersion was subsequently sonicated and lyophilized. This protocol introduces a small concentration of sulfate ester groups on the surface of the CNCs, which help to form stable suspensions in polar solvents. ${ }^{50}$ In our previous work $^{\mathbf{3 0 , 3 1}}$ we presented data on the synthesized cellulose nanocrystals (CNCs) in terms of particle morphology, crystal structure, concentration of sulfate groups in the surface and properties. CNCs present a needle-like structure with and average aspect ratio (length : width) of $11 \pm 1$ with an average width of $18 \pm 2 \mathrm{~nm}$ and an average length of $199 \pm 14 \mathrm{~nm}$. The crystal structure of the CNCs is cellulose I and the apparent crystallinity is $69 \%$, the sulfate content is $91 \pm 4 \mathrm{mM} \mathrm{kg}_{\text {cellulose }}{ }^{-1}$.

\subsection{Synthesis of PMS pre-polymer}

Sebacic acid (SA) and D-mannitol (MA) were reacted in a manner described previously. ${ }^{1}$ PMS pre-polymer (pre-PMS) was synthesized to obtain 1:2 mannitol : sebacic acid ratio. ${ }^{31}$ Briefly, appropriated molar amounts $(0.034: 0.068)$ of MA $(6.21 \mathrm{~g})$ and SA $(13.79 \mathrm{~g})$ were charged into a $250 \mathrm{~mL}$ three-necked roundbottom flask equipped with a stirrer and a condenser, which was placed in an oil heating bath and purged for $0.5 \mathrm{~h}$ with nitrogen. The temperature was slowly increased to $150{ }^{\circ} \mathrm{C}$ under continuous stirring and nitrogen flow to produce approximately $20 \mathrm{~g}$ of pre-polymer. The reaction was stopped after $5 \mathrm{~h}(1 \mathrm{~h}$ before gelation occurs), and the pre-polymer was dissolved in DMF (150 $\mathrm{mg} \mathrm{mL}^{-1}$ ), filtered and purified by dropwise precipitation into a four-fold excess of cold ultrapure water under continuous stirring. The precipitated pre-polymer was collected and dried under vacuum until no more solvent was detected in the infrared spectra. The yield of the reaction was $\sim 88 \%$, as calculated from the weight of the monomers before reaction and the weight of obtained pre-polymer after reaction. A composition of mannitol : sebacic acid of $0.83: 2$ determined by ${ }^{1} \mathrm{H}-\mathrm{NMR}$ was achieved. ${ }^{31}$

\subsection{Production of nanofibers mats}

Poly(lactic acid) (PLA) was electrospun into a nanofiber mat (NFPLA) through electrospinning method following a previously reported protocol, ${ }^{51}$ to obtain average fiber diameters nearly to 300-400 $\mathrm{nm}$ and electrospun mat thickness around $100 \mu \mathrm{m}$. Briefly, $10 \mathrm{~mL}$ of viscous polymer solution with a concentration of $7 \% \mathrm{w} / \mathrm{v}$ was prepared by dissolving PLA (3051D) in a mixture solvent system with dichloromethane and $\mathrm{N}, \mathrm{N}$ dimethylformamide (DCM : DMF 70:30). The solution was injected using a $10 \mathrm{~mL}$ disposable syringe with a $22 \mathrm{G}$ needle connected to the positive terminal of the high voltage supply. All air bubbles were purged prior to electrospinning and the applied voltage was kept at $14 \mathrm{kV}$, the distance between the charged capillary tip and the collector mandrel was $13 \mathrm{~cm}$, and the flow rate of the solution was always kept at $0.6 \mathrm{~mL} \mathrm{~h}^{-1}$, controlled by a syringe infusion pump. The collector mandrel was covered with aluminium foil, and a take-up velocity (rotation speed of the mandrel) of $1100 \mathrm{rpm}$ was used.

\subsection{Preparation of PMS/CNC nanocomposites}

Previously reported protocol was followed to prepare films of neat PMS (1:2 MA : SA ratio) and poly(mannitol sebacate)/ cellulose nanocrystals (PMS/CNC) nanocomposites with 1, 5 and $10 \%$ of filler content (Scheme 1). ${ }^{31}$ In brief, appropriate amounts of CNCs were dispersed by ultrasonic treatment at a concentration of $10 \mathrm{mg} \mathrm{mL}^{-1}$ in DMF. CNCs suspensions were mixed under vigorous stirring with solutions of PMS prepolymer in DMF $\left(10 \mathrm{mg} \mathrm{mL} \mathrm{mL}^{-1}\right)$. The resultant mixtures were cast into Petri dishes and allowed to dry in an oven at $70{ }^{\circ} \mathrm{C}$. The resulting pre-polymer/nanocomposites and the neat prepolymer films obtained by applying this protocol (after step 3 in Scheme 1), were placed in a vacuum oven for further reaction at $120{ }^{\circ} \mathrm{C}$ for 72 hours and under $60 \mathrm{~cm} \mathrm{Hg}$ to afford films of 150-200 $\mu \mathrm{m}$ of thickness of neat PMS and PMS/CNC final samples (step 4 in Scheme 1).

\subsection{Preparation of PMS/NF-PLA nanocomposites}

The methodology schematically shown in Scheme 2 was used to prepare poly(mannitol sebacate)/nanofiber nanocomposites (PMS/NF-PLA), from previously obtained pre-PMS (1 : 2 MA : SA ratio $^{31}$ and electrospun PLA mats (NF-PLA). Samples with different amount of layered mats of NF-PLA (according to the number of layers used: 1, 2 and 3 mats), were obtained by cutting a rectangular area of dimensions $4 \times 8 \mathrm{~cm}$ from an electrospun mat and infiltrating them into the pre-PMS. Briefly, nanocomposites with different matrix/nanofibers weight percentage ratio were produced using a stratification technique by means of which, $0.6 \mathrm{~g}$ of pre-polymer were combined with 1 , 2 and 3 layers of electrospun NF-PLA mats. The pre-polymer was heated at $40{ }^{\circ} \mathrm{C}$ (as it starts to be a viscous clear liquid at this temperature losing the waxy aspect) and spread into a Teflon® surface, appropriate amounts of previously cut NF-PLA mat fragments were then immersed while vacuum $(30 \mathrm{~cm} \mathrm{Hg})$ was 

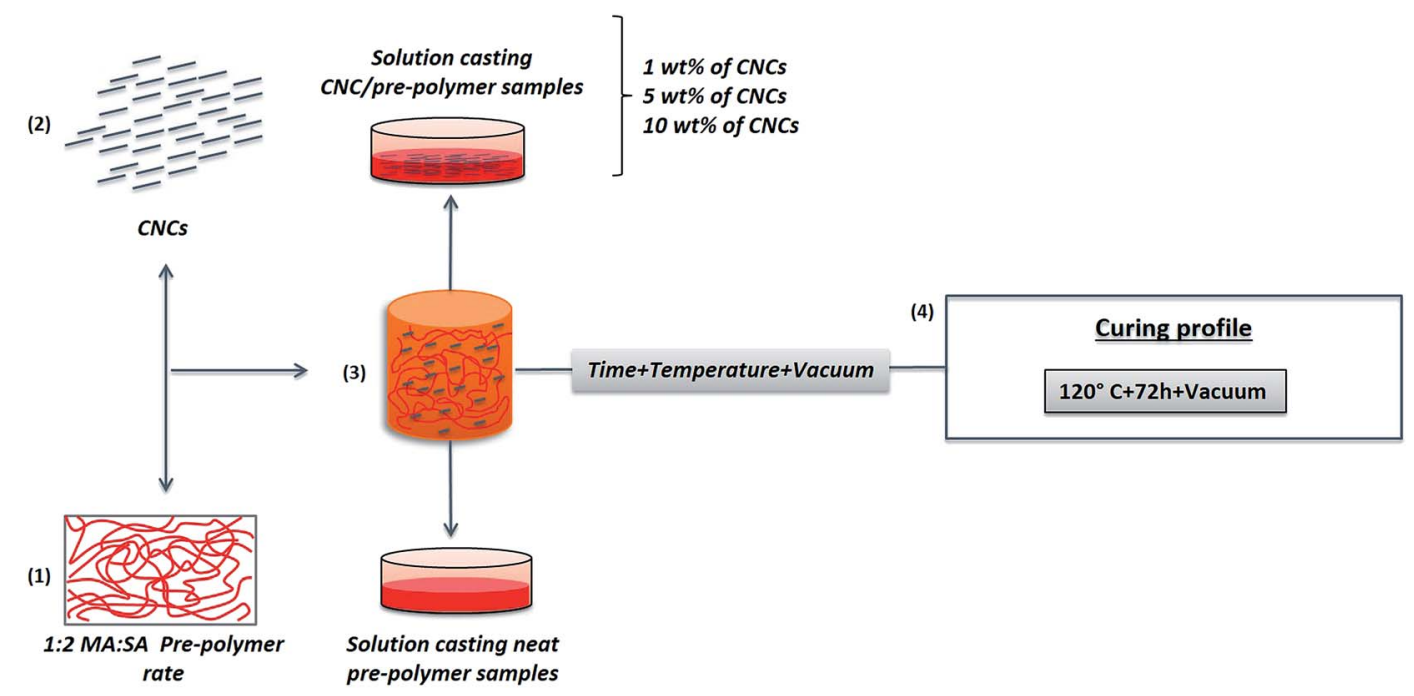

Scheme 1 Schematic representation of the methodology followed to obtain all the PMS/CNC nanocomposites. Solutions of pre-polymer in DMF (1) were mixed with CNC suspensions also in DMF (2). Mixtures obtained and neat pre-polymer solutions were casted (3) and after evaporation of the solvent, samples were crosslinked through further polycondensation step (4).

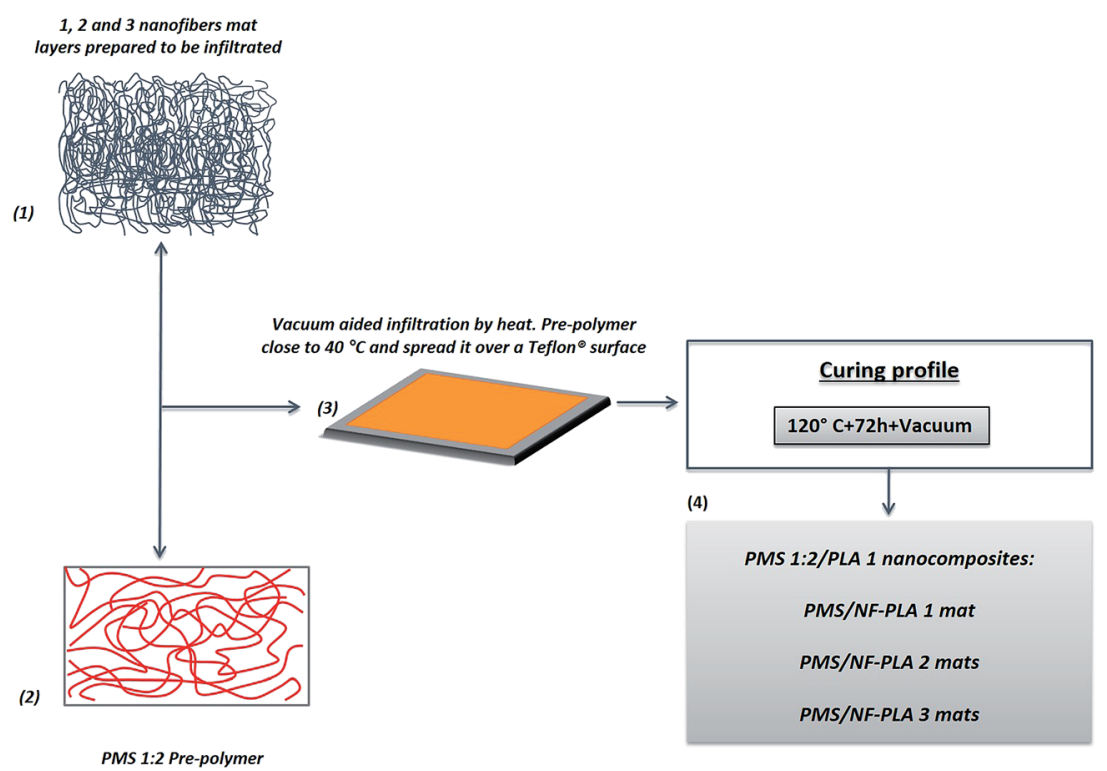

Scheme 2 Schematic representation of the methodology followed to obtain all the PMS/NF-PLA nanocomposites. Electrospun PLA mats (1) were infiltrated into spread pre-polymer PMS $1: 2$ (2) over a Teflon® surface (3) with the help of vacuum and temperature. After infiltration, further polycondensation step under low curing designed profile was carried out (4).

applied for 20 min to ensure complete infiltration of pre-PMS into the NF-PLA mats (steps 1-3 in Scheme 2). Afterwards, the pre-PMS/NF-PLA nanocomposites were placed in a vacuum oven (at the same conditions that pre-PMS/CNC nanocomposites) (step 4 in Scheme 2) for further reaction of the matrix to obtain final crosslinked PMS/NF-PLA samples. Previously to infiltration, the NF-PLA mats and the amount of pre-PMS used in each sample were weighed, as well as the obtained nanocomposites after curing. Final weight ratio between nanofibers and matrix were then calculated to be 4,10 and $15 \mathrm{wt} \%$ with the addition of 1, 2 and 3 layers of electrospun NF-PLA mats respectively.

\subsection{Swelling and degradation studies in SBF}

The swelling degree and degradation studies of all obtained samples ( $n=4,5 \times 5 \mathrm{~mm}, 150-200 \mu \mathrm{m}$ thickness) were studied under physiological conditions, in simulated body fluid solution (SBF) of pH $7.4 \pm 0.5$ at $37^{\circ} \mathrm{C}$, prepared following a previously reported protocol. ${ }^{52}$ For swelling studies, samples were collected after a 24 hour hydration period in SBF, blotted with a filter paper to remove excess surface water, and weighed (swelled weight; $W_{\mathrm{s}}$ ). The swelling percentage of the networks after $24 \mathrm{~h}$ was determined comparing the swelled weight $\left(W_{\mathrm{s}}\right)$ with the initial weight $\left(W_{\mathrm{o}}\right)$ using eqn (1). 


$$
\text { Swelling degree }(\%)=\frac{W_{\mathrm{s}}-W_{\mathrm{o}}}{W_{\mathrm{o}}} \times 100
$$

The degradation behavior was determined by monitoring the weight loss at different times. Samples were weighed, immersed in $15 \mathrm{~mL}$ of SBF and incubated at $37^{\circ} \mathrm{C}$ in an oven for various periods of time. Nanocomposites samples were removed from SBF at different time intervals ( 14 days, 28 days, 42 days, 56 days and 150 days), thoroughly washed with distilled $\mathrm{H}_{2} \mathrm{O}$ and dried under vacuum at $37^{\circ} \mathrm{C}$ until constant weight was reached. To the degradation study of neat PMS and PMS/NF-PLA nanocomposites, two longer degradation time intervals, at 210 days (7 months) and 240 days ( 8 months), were incorporated. The degradation degree of the polymers in SBF was calculated averaging the values of three samples, by comparing the mass at each time interval $\left(M_{t}\right)$ with the initial mass $\left(M_{\mathrm{o}}\right)$ using eqn (2).

$$
\text { Mass } \operatorname{loss}(\%)=\frac{M_{\mathrm{o}}-M_{t}}{M_{\mathrm{o}}}
$$

\subsection{Scanning electron microscopy (SEM)}

Morphological investigation of PLA electrospun nanofibers mat and cross-section of the PMS/NF-PLA nanocomposites were carried out by means of a JEOL JSM6030 scanning electron microscope. Nanofibers mats samples were prepared by cutting square pieces from randomly chosen parts of the processed specimen, while nanocomposites were cryo-fractured under liquid nitrogen. Specimens were gold-coated to minimize the charging effect during SEM observation as well as give enough conductivity to the sample. Operating conditions were set at 10 $\mathrm{kV}$ of accelerating voltage and a working distance of 10-15 mm.

\subsection{Mechanical microtesting}

Tensile tests were carried out on a DEBEN microtester equipped with a $150 \mathrm{~N}$ load cell and operated at a crosshead speed of 0.4 $\mathrm{mm} \min ^{-1}$ at room temperature. Specimen dimensions were typically $15 \times 4 \mathrm{~mm}$. The elongation to break, Young's modulus, toughness and ultimate tensile strength were analysed for samples at initial stage (day 0 of degradation). Young's modulus of degraded samples was analysed at different degradation stages (immersion in SBF at pH $7.4 \pm 0.5$ at $37^{\circ} \mathrm{C}$ for 1,28 and 150 days). Degraded samples were taken out from SBF and immediately tested. For each sample, a minimum of 5 rectangular samples were tested and the mechanical data were averaged.

\subsection{Thermogravimetric analysis (TGA)}

Thermal stability of all obtained samples was recorded in a Mettler-Toledo TGA/SDTA 851 modulus analyser. The samples (5-10 mg) were weighed in zirconium crucibles and heated in air at a rate of $10^{\circ} \mathrm{C} \mathrm{min}^{-1}$ from ambient temperature to $700^{\circ} \mathrm{C}$. Thermal stability temperatures were acquired as onset temperatures $\left(T_{\mathrm{o}}\right)$, obtained by a tangential intercept method onto the TG curve. The electrospun NF-PLA mats were also analysed for reference purposes.

\subsection{Dynamic mechanical thermal analysis (DMTA) and thermally activated shape-memory properties}

The mechanical behavior as a function of temperature was characterized by DMTA measurements on a TA Q800 instrument (TA instruments). Samples were cut into $30 \times 4 \mathrm{~mm}$ rectangular shapes and tested in tensile mode with a temperature ramp method from -50 to $150^{\circ} \mathrm{C}$ at a heating rate of $3{ }^{\circ} \mathrm{C}$ $\min ^{-1}$. Frequency and strain amplitude were kept constant at $1 \mathrm{~Hz}$ and $15 \mu \mathrm{m}$, respectively. Glass transition temperatures were calculated as the maximum in tangent delta peak. Shapememory characteristics of the samples were quantified by cyclic, thermomechanical tensile tests in the DMTA. The experiment involved the creation of a temporary shape in a programming mode and a free stress recovery step of the permanent shape. The programming mode was performed under strain-controlled conditions in three steps: (1) the sample was equilibrated at $45{ }^{\circ} \mathrm{C}$ for $10 \mathrm{~min}$, before a force ramp of $3 \mathrm{~N} \mathrm{~min}^{-1}$ was applied until a strain of $30 \%$ was reached. (2) While the stress was kept constant, the sample was subsequently cooled to $15^{\circ} \mathrm{C}$. (3) The sample was unloaded to zero stress and the temperature was maintained at $15{ }^{\circ} \mathrm{C}$ for $5 \mathrm{~min}$ to ensure the fixation of the temporary shape. At this point, the recovery step was initiated by increasing the temperature to $45^{\circ} \mathrm{C}$, which was then maintained for $20 \mathrm{~min}$. All samples were tested for 3 or 4 cycles. The ability to fix the temporary shape at $15{ }^{\circ} \mathrm{C}$ (shape fixity ratio, $R_{\mathrm{f}}$ ) and the ability to recover the permanent shape at $45^{\circ} \mathrm{C}$ (shape recovery ratio, $R_{\mathrm{r}}$ ) were quantified using the following equations $s^{53-55}$

$$
\begin{gathered}
R_{\mathrm{f}}(N)=\frac{\varepsilon_{\mathrm{u}}(N)}{\varepsilon_{\mathrm{m}}(N)} \times 100 \% \\
R_{\mathrm{r}}(N)=\frac{\varepsilon_{\mathrm{m}}(N)-\varepsilon_{\mathrm{f}}(N)}{\varepsilon_{\mathrm{m}}(N)-\varepsilon_{\mathrm{f}}(N-1)} \times 100 \%
\end{gathered}
$$

where $\varepsilon_{\mathrm{m}}$ is the maximum strain achieved in the $N^{\text {th }}$ cycle after cooling and before unloading, $\varepsilon_{\mathrm{u}}$ is the fixed strain after unloading the sample at $15{ }^{\circ} \mathrm{C}$ in the same cycle and $\varepsilon_{\mathrm{f}}$ is the residual strain of the sample after the recovery step. The shapememory temperature profiles where selected based on the results obtained in the DMTA analysis and in order to fulfil the requirements for potential biomedical applications, thus shapememory biomedical devices are recommended to be activated in the range of $36-55^{\circ} \mathrm{C}$, being desirable this range as is close to the physiological temperature as well as to avoid premature activation at room temperature. ${ }^{56}$

\section{Results and discussion}

\subsection{Properties of reinforcing fillers}

The most important properties of the isolated CNCs (by hydrolysis of cotton with sulfuric acid) used in the present work, were characterized and reported in our previous work. ${ }^{30,31}$ The morphology of PMS/NF-PLA nanocomposites was studied by scanning electron microscopy (SEM). Fig. 1a and b show a representative SEM image and a histogram of PLA fiber diameters (obtained by image analysis), respectively. These 
figures display a uniform and bead-free fiber morphology produced by electrospinning with an average diameter of $365 \pm$ $101 \mathrm{~nm}$.

For all PMS/NF-PLA nanocomposites, cross-sectional SEM revealed a sandwich-type structure, showing that the infiltration was complete with all the original voids occupied by the PMS matrix (Fig. 1c and ESI S1 $\dagger$ ). The PMS matrix seems to be well-interfaced with the electrospun mats without an evident delamination. In this regard, a rough surface area is shown, which indicates that electrospun PLA-reinforced nanocomposites require more energy to delaminate. In Fig. 1d the fiber structure is preserved after applying the necessary processing conditions (vacuum and temperature). The electrospun nanofiber mat shows improved bonding with the PMS matrix. The nanofibers appear broken on the same plane with the matrix and do not exhibit a clear pull-out or debonding.

\subsection{Characterization of initial samples}

3.2.1. Mechanical testing. In order to evaluate the mechanical properties of the PMS nanocomposites with different contents of CNC and PLA nanofibers, micro-tensile tests were carried out. The average tensile Young's modulus, ultimate tensile strength, and elongation at break and toughness for all samples are summarized in Table 1.
The effect of nanocellulose content on the mechanical properties of PMS was discussed in our previous work ${ }^{\mathbf{3 0 , 3 1}}$ however, the purpose of the present paper is the comparison between the different fillers used. The addition of CNCs to the PMS matrix was found to improve its mechanical properties. In particular, it led to a noticeable increase in the Young's modulus, even for low contents of CNC, being the presence of the well-dispersed nanocrystals together with the filler-filler and polymer-filler interactions the main mechanisms responsible for the better mechanical properties of the nanocomposites. The reinforcement of the PMS matrix upon addition of 4, 10 and $15 \mathrm{wt} \%$ of PLA nanofibers was indicated by increases in elastic modulus, UTS and toughness as filler content increased. In addition, a similar elongation was observed for all electrospun PLA nanofiber-reinforced nanocomposites. Both, the higher elongation and the noticeable enhancement of the mechanical properties for this system in comparison with the CNC/PMS nanocomposites, are probably due to the semicrystalline nature of the PLA as well as the strong interactions and adhesion between the higher modulus nanofibers and the low modulus PMS matrix, resulting in a more effective stress transfer and enhancement of the overall strength of the material during stretching.

As is seen in Fig. 2, a low content of PLA nanofibers (4 wt\%) results in better behavior than that of the neat matrix, but lower

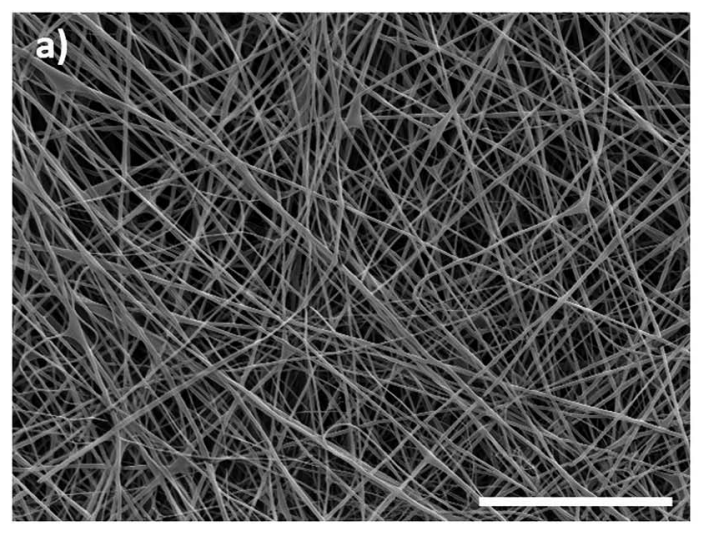

b)
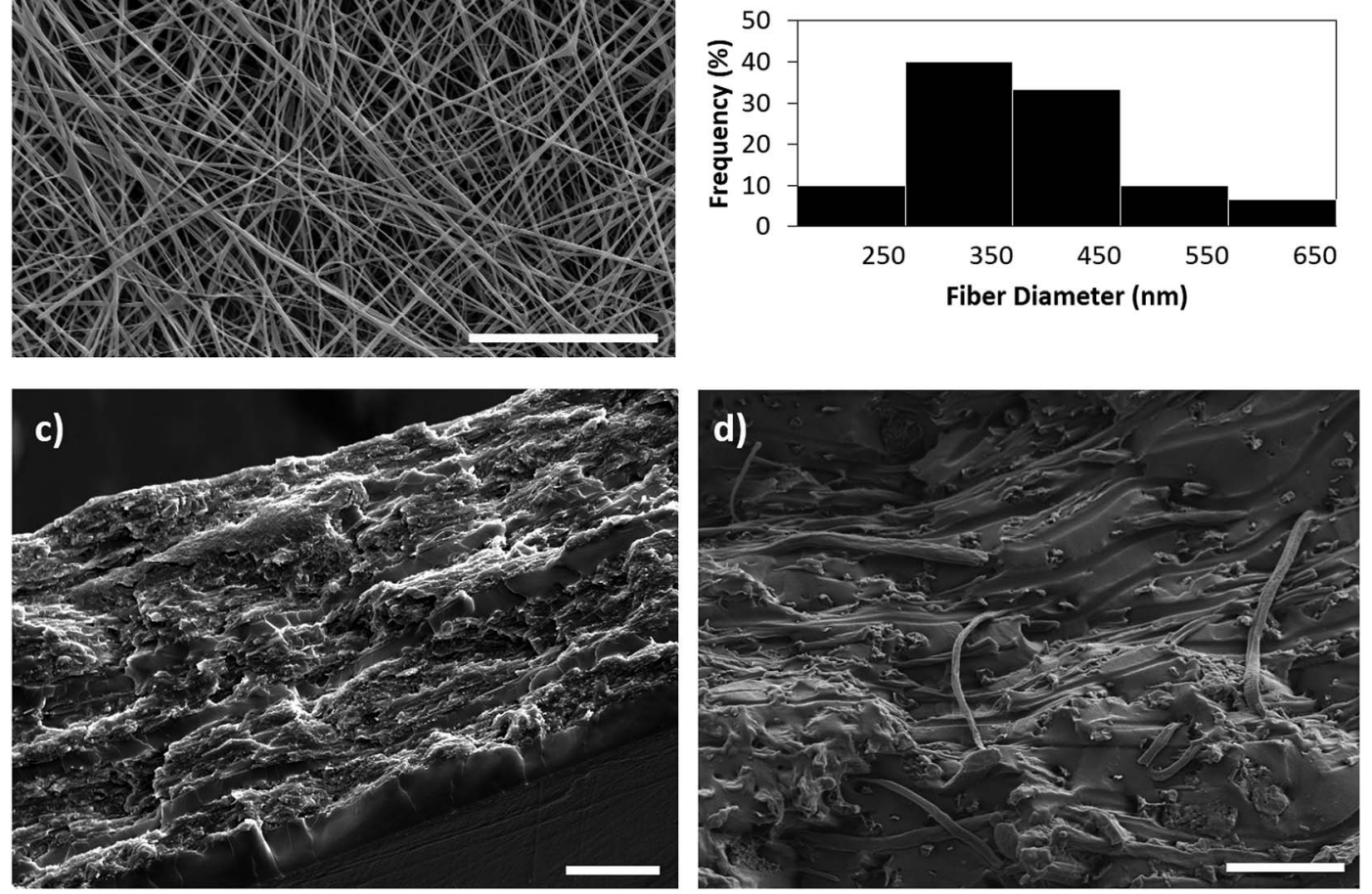

Fig. 1 SEM image of the surface morphology of the electrospun nanofiber PLA mat (scale bar $20 \mu \mathrm{m}$ ) (a), fiber diameter distribution histogram (b), cross-sectional SEM of PMS/NFPLA 15 wt\% nanocomposite (scale bars 20 and $2 \mu \mathrm{m}$ respectively) (c and d). 
Table 1 Main mechanical properties of neat PMS, PMS/CNC and PMS/NF-PLA nanocomposites

\begin{tabular}{|c|c|c|c|c|}
\hline Sample & Young's modulus $^{a}(\mathrm{MPa})$ & $\begin{array}{l}\text { Ultimate tensile } \\
\text { strength (MPa) }\end{array}$ & $\begin{array}{l}\text { Elongation at } \\
\text { break (\%) }\end{array}$ & Toughness $\left(\mathrm{MJ} \mathrm{m}^{-3}\right)$ \\
\hline NF-PLA & $125.6 \pm 6.5$ & $3.7 \pm 1.0$ & $48.5 \pm 5.7$ & $196.4 \pm 23.4$ \\
\hline PMS $/ 10 \%$ NF-PLA & $142.7 \pm 3.3$ & $7.3 \pm 1.1$ & $32.2 \pm 3.5$ & $156.8 \pm 21.0$ \\
\hline PMS/15\% NF-PLA & $380.3 \pm 5.5$ & $14.0 \pm 1.4$ & $37.0 \pm 5.6$ & $427.0 \pm 54.1$ \\
\hline Neat $\mathrm{PMS}^{b}$ & $7.2 \pm 0.1$ & $4.5 \pm 0.7$ & $35.8 \pm 3.5$ & $81.8 \pm 5.4$ \\
\hline $\mathrm{PMS} / 10 \% \mathrm{CNC}^{b}$ & $32.3 \pm 2.6$ & $8.5 \pm 2.0$ & $23.4 \pm 0.1$ & $89.3 \pm 39.1$ \\
\hline
\end{tabular}

${ }^{a}$ Young's modulus was calculated for PMS/CNC nanocomposites from the initial slope between 0 and 10\%. For PMS/NF-PLA nanocomposites and NF-PLA was calculated between 0 and $1 \%$ of strain. ${ }^{b}$ Values from ref. 31.

than that of the nanofibers alone; however, by increasing the PLA nanofiber content to over $10 \mathrm{wt} \%$, a synergic effect between the filler and the matrix occurs, resulting in a marked enhancement in mechanical properties. In comparison with the results obtained in the PMS/CNC nanocomposites (Table 1), the introduction of $4 \mathrm{wt} \%$ of PLA nanofibers results in a similar elastic modulus and a higher elongation at break than PMS/ CNC nanocomposites with $10 \mathrm{wt} \%$ of CNCs. In contrast, nanocomposites with $15 \mathrm{wt} \%$ of PLA nanofiber content results in a much greater enhancement of the mechanical properties achieving a 50-fold enhancement of the Young's modulus. UTS and toughness are also increased 3 -fold and 5-fold, respectively, for this sample.

Thanks to the higher stiffness of the CNCs as compared to the pure matrix, as well as the possibility to highly interact with it, due to the high -OH functionality, this filler has been proven to markedly enhance the reinforcing properties of the PMS more efficiently than similar reported systems with inorganic fillers such as Bioglass ${ }^{\circledR} .{ }^{57}$ However, the contribution to the mechanical properties of the PLA nanofibers over the PMS matrix was seen to be more efficient than that of the CNCs. In this regard, the electrospun PLA nanofibers provide

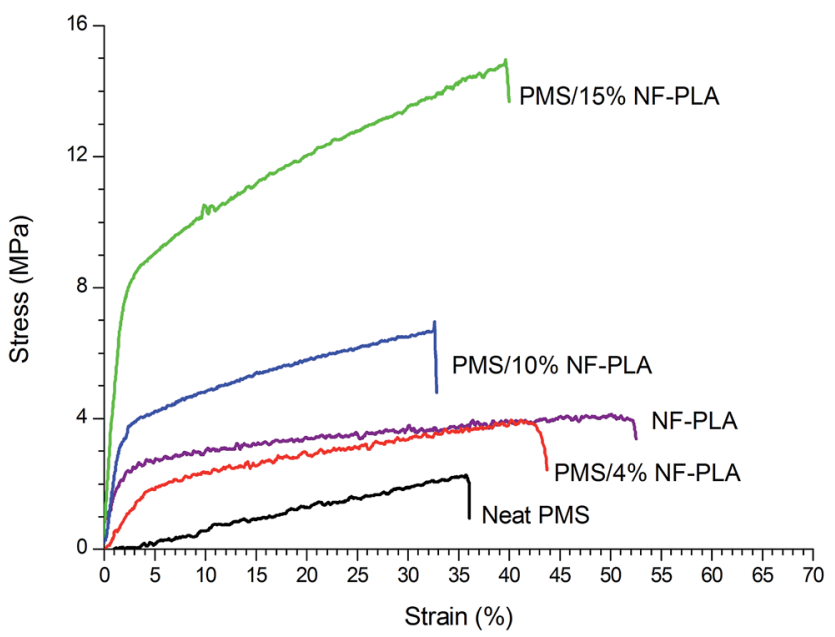

Fig. 2 Typical tensile stress versus strain curves registered at room temperature for PMS/NF-PLA nanocomposites. a significant increase in plastic deformation due to their polymeric nature and their good interfacial adhesion with the matrix, which results in nanocomposites with enhanced toughness and strength. Although both fillers have nanosized morphology, the NF-PLA have a higher aspect ratio (diameter to length relation) and a larger surface area to volume ratio (providing an interconnected reinforcing phase) in comparison to CNCs. These facts considerably increase the interphase area (contact area) between the matrix and the reinforcing filler and resulted in a much more effective reinforcing effect and superior mechanical performance of these nanocomposites.

3.2.2. Thermogravimetric analysis. Table 2 shows the onset degradation temperature values for all developed samples. In regard to the thermal stability of PMS/CNC nanocomposites, these values revealed a slight increase in thermal stability for low CNC contents (1 wt\%); this stability decreases with increasing filler content ( 5 and $10 \mathrm{wt} \%$ of CNC) probably due to CNC's lower onset degradation temperature relative to that of the matrix. The first degradation CNC process typically starts close to $220{ }^{\circ} \mathrm{C}$ and is associated with the CNC glycosyl units degradation..$^{58}$

However, the opposite phenomenon occurs in PMS/NF-PLA nanocomposites, as the degradation onset temperature increases with the NF-PLA content up to $4 \mathrm{wt} \%$ on account of the higher thermal stability of the nanofibers $\left(334.5{ }^{\circ} \mathrm{C}\right)$

Table 2 Hydration by mass and thermal properties of PMS and PMS nanocomposites

\begin{tabular}{lllll}
\hline Sample & & & $\begin{array}{l}T_{\text {ONSET }}{ }^{b} \\
\left({ }^{\circ} \mathrm{C}\right)\end{array}$ & $\begin{array}{l}\text { Hydration by } \\
\text { mass }(\%)\end{array}$ \\
\hline PLA NF & - & 82.6 & 334.5 & $20.7 \pm 1.6$ \\
PMS/4\% NF-PLA & 26.8 & 84.1 & 235.4 & $12.4 \pm 1.1$ \\
PMS/10\% NF-PLA & 23.0 & 85.5 & 244.4 & $6.3 \pm 1.1$ \\
PMS/15\% NF-PLA & 20.4 & 85.2 & 261.3 & $5.4 \pm 1.3$ \\
Neat PMS & 23.4 & - & $238.0^{c}$ & $14.4 \pm 1.0^{c}$ \\
PMS/1\% CNC & 23.0 & - & $238.6^{c}$ & $12.0 \pm 0.3^{c}$ \\
PMS/5\% CNC & 19.1 & - & $233.7^{c}$ & $11.4 \pm 0.3^{c}$ \\
PMS/10\% CNC & 18.4 & - & $232.8^{c}$ & $10.4 \pm 0.8^{c}$
\end{tabular}

${ }^{a}$ Glass transition temperatures were calculated as the delta tangent peak from DMTA curves (ESI Fig. S4). ${ }^{b}$ Determined from the onset of degradation from TGA curves. ${ }^{c}$ Values from ref. 31. 
compared to that of the neat matrix $\left(238.0{ }^{\circ} \mathrm{C}\right)$. The nanocomposite with $4 \mathrm{wt} \%$ of NF-PLA has similar degradation onset temperature to that of the neat matrix which represents most of the material. However, with $10 \mathrm{wt} \%$ of NF-PLA, thermal stability is improved by around $9{ }^{\circ} \mathrm{C}$; with $15 \mathrm{wt} \%$ of NF-PLA, the stability increases more considerably, by around $26{ }^{\circ} \mathrm{C}$.

3.2.3. DMTA testing. DMTA was used to determine the mechanical properties of all the systems as a function of temperature. Fig. 3a and b show the DMA curves of the storage modulus for PMS/CNC and PMS/NF-PLA nanocomposites, respectively. In the glassy state, all DMA curves follow the same general trend; thus, the storage modulus $\left(E^{\prime}\right)$ is only slightly increased by adding CNCs or NF-PLA contents lower than 10 wt\%, which is consistent with the observations in both our previously reported system (based on a PMS 1:1 matrix) and those of other studies (based on glassy matrices reinforced with nanofillers) ${ }^{30,58}$ However, the introduction of high amounts of CNCs (10 wt\%) and NF-PLA (10-15 wt\%) fillers leads to a clear reinforcement in the glassy-state storage modulus. The storage modulus of neat PMS increases from $2600 \mathrm{MPa}$ to $3500 \mathrm{MPa}$ by adding $10 \mathrm{wt} \%$ of CNCs, and by the addition of 10 and $15 \mathrm{wt} \%$ of NF-PLA storage modulus values of 3000 and $4750 \mathrm{MPa}$ are reached, respectively. The PMS/CNC nanocomposites exhibit a $T_{\mathrm{g}}$ (from DMTA) between 18 and $23{ }^{\circ} \mathrm{C}$ (Table 2 and ESI Fig. S3a $\dagger$ ). These values are consistent with those previously reported from Differential Scanning Calorimetry (DSC) for these materials. ${ }^{31}$ Thus, $T_{\mathrm{g}}$ slightly decreases with increasing the CNC content, probably due to the disruption of the PMS polymeric network along with strong interactions between filler and matrix thus, decreasing the $T_{\mathrm{g}}$ of the global system. ${ }^{59}$ Similar behavior was also observed in PGS bioglass nanocomposites and polyurethane systems reinforced with CNCs. ${ }^{57,60}$ Regarding to the PMS/NF-PLA nanocomposites (Fig. 3b), as was expected, two different clear transitions appeared in the storage modulus; these can be attributed to the glass transition of PMS (in the range of $21-26^{\circ} \mathrm{C}$ ) and the glass transition of NF-PLA (in the range of $83-85^{\circ} \mathrm{C}$ ), as determined from the tangent delta peaks (ESI Fig. S3b $\dagger$ ). In contrast, both the PMS matrix and the PMS/ CNC nanocomposites have only one transition, which is related to the glass transition of the neat matrix; however, the reinforcing effect induced by the fillers appears to be much more significant as the temperature increases to the rubbery plateau (above $40{ }^{\circ} \mathrm{C}$ ).

In addition, the storage modulus in the rubbery plateau above glass transition of the neat PMS matrix also increases as the filler content increases for both types of nanocomposite systems (CNCs and NF-PLA reinforced). By introducing a 10 wt\% of NF-PLA content, the storage modulus is increased to $280 \mathrm{MPa}$, more than 3 times higher than the value obtained for the same CNCs content sample. Thus, a pronounced reinforcing effect is achieved by introducing nanofibers, with storage modulus values as high as $445 \mathrm{MPa}$ at $45{ }^{\circ} \mathrm{C}$ (after PMS glass transition) for $15 \mathrm{wt} \%$ of NF-PLA content (Fig. 3b). This trend is in accordance with the results obtained in tensile tests at room temperature, in which the Young's modulus increases markedly with the wt\% of the NF-PLA addition. The fact that the rubbery plateau between the glass transition of the PMS matrix and the glass transition of the reinforcing NF-PLA becomes more pronounced as the filler content increases is in account of the larger surface area (compare to the CNCs) combined with a good adhesion and strong interactions between the PMS and the NF-PLA that ensure a better stress transfer from the matrix to the reinforcing phase in these nanocomposites. ${ }^{61}$ For the same reasons, comparing all the developed materials at high temperatures $\left(85-90^{\circ} \mathrm{C}\right)$, the highest $E^{\prime}$ values are also observed for the PMS/NF-PLA nanocomposites with values between 25 and $120 \mathrm{MPa}$. The reinforcement effect in the rubbery plateau above the PMS $T_{\mathrm{g}}$ observed for all the nanocomposite samples is crucial for shape-memory behaviour and is comparable with values reported in the literature that were obtained in materials with good shape-memory properties. ${ }^{47,62}$ However as it will be shown further, the double stepwise decrease of the $E^{\prime}$ upon PMS $T_{\mathrm{g}}$ and NF-PLA $T_{\mathrm{g}}$ will be of interest for a better shape-memory performance in the range of the temperatures useful for biomedical applications.

3.2.4. Thermally activated shape-memory properties. The shape-memory properties were determined by cyclic thermomechanical tests conducted in a DMTA, quantifying shape recovery $\left(R_{\mathrm{r}}\right)$ and shape fixity $\left(R_{\mathrm{f}}\right)$ ratios for each cycle by applying the method detailed in the experimental section. The
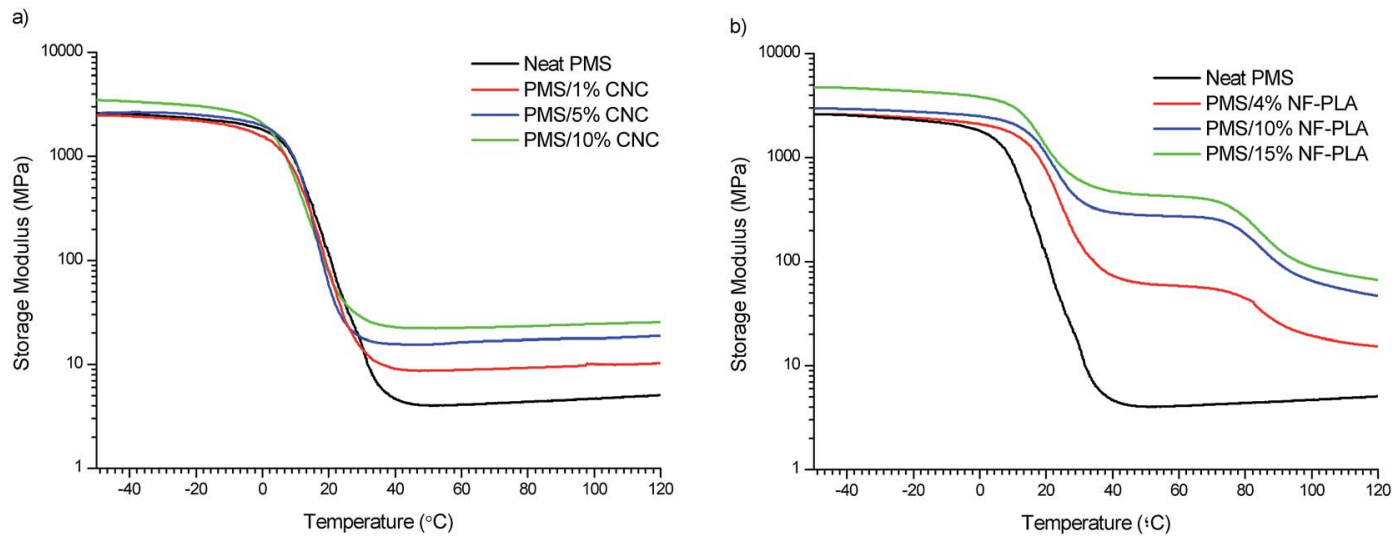

Fig. 3 Storage modulus ( $\left.E^{\prime}\right)$ as a function of temperature for PMS/CNC nanocomposites (a) and PMS/NF-PLA nanocomposites (b). 
shape-memory properties were determined by cyclic thermomechanical tests conducted in a DMTA, quantifying shape recovery $\left(R_{\mathrm{r}}\right)$ and shape fixity $\left(R_{\mathrm{f}}\right)$ ratios for each cycle by applying the method detailed in the Experimental section. As was observed in previous studies, the fact that $R_{\mathrm{r}}$ values are higher for the second thermo-mechanical cycle is related with the less plastic and non-reversible deformation (hysteresis) compared to the first thermo-mechanical cycle as was observed in previous studies. ${ }^{30}$ Fig. 4 shows an example of the shapememory cycles measured for PMS/CNC and PMS/NF-PLA nanocomposites with $10 \mathrm{wt} \%$ of CNC and NF-PLA respectively. Under the conditions chosen for the shape-memory test, all the samples reinforced with CNCs have an incomplete shape fixation $\left(R_{\mathrm{f}}<50 \%\right)$ of the programmed shape after cooling and unloading the applied stress, probably due to the fact that the fixing temperature $\left(T_{\text {low }}\right)$ is in the vicinity of the $T_{g}\left(18-23{ }^{\circ} \mathrm{C}\right)$. This was observed in previously reported similar systems, ${ }^{30}$ which also resulted in insufficient shape-memory behavior.

By contrast with the previously discussed PMS/CNC nanocomposites (employing NF-PLA as reinforcement fillers), enhanced shape-memory properties are imparted to the system. All PMS/NF-PLA nanocomposites showed a marked shapememory effect, with an increase in shape fixity (Fig. 5a) as the filler content increases after unloading at $T_{\text {low. }}$. The nanofibers' presence helps constrain the premature recovery of the matrix, which occurs in PMS and PMS/CNC nanocomposites that are not able to fix the shape. Importantly, nanofibers played a significant role in maintaining the shape of the PMS matrix above its $T_{\mathrm{g}}$. Shape fixity ratio values $\left(R_{\mathrm{f}}\right)$ were 72,87 and $91 \%$ for PMS with 4, 10 and $15 \mathrm{wt} \%$ of PLA nanofibers respectively. In case of the shape recovery for the first cycle (Fig. 5b) there is a loss in $R_{\mathrm{r}} \%$ with increasing NF-PLA content, but the second cycle stabilizes at values of $99-100 \%$. Thus, the fibers's possible plastic deformation (as they are above their glass transition during deformation and recovery) seems not to impede the system's recovery, and the PMS matrix chains' mobility and rubber elasticity at $45{ }^{\circ} \mathrm{C}$ achieve a good global recovery. One can surmise that this phenomenon is the result of a complete infiltration of the mats inside the matrix, resulting in a synergic effect of both components. It should be pointed out that for a PMS/NF-PLA sample with $4 \mathrm{wt} \%$, shape recovery starts at a temperature slightly higher than the neat PMS $T_{\mathrm{g}}\left(\sim 30^{\circ} \mathrm{C}\right)$; however, by increasing the nanofiber content to 10 and $15 \mathrm{wt} \%$, the relaxation processes during the shape-memory test occur at temperatures in the range of $40-45^{\circ} \mathrm{C}$. This fact is of interest to avoid the premature recovery of a possible biomedical device during implantation.

In general, the main goal of the concept introduced in this work is to achieve design flexibility by using nanofibers as a reinforcement phase to impart shape-memory properties that cannot be achieved by fillers with the morphology of CNCs. It should be pointed out that the temperatures at which the reinforcement effect occurs in the DMTA curves is a key factor in the usefulness of the PMS/NF-PLA nanocomposites as shape-memory materials for biomedical applications. In addition, a clear enhancement in the shape fixity $\left(R_{\mathrm{f}} \%\right)$ ratios could be reached by increasing the $w t \%$ of NF-PLA content of the matrix. On the other hand, since the shape recovery process is thermally dependent, ${ }^{63}$ the recovery ratios $\left(R_{\mathrm{r}} \%\right)$ can be improved by increasing the recovery temperature to make it closer to the nanofibers' $T_{\mathrm{g}}$ or by employing nanofibers with lower glass transitions to allow partial mobility of the chains at the temperature of interest. It is also remarkable that the higher stress during shape-memory cycles ( $\sim \mathrm{MPa})$ is reached with PMS/NF-PLA $15 \mathrm{wt} \%$ nanocomposite, in agreement with the improvement in the Young's modulus and storage modulus $\left(E^{\prime}\right)$ at the rubbery plateau observed for this sample. This fact is reported to be concomitant with a higher shape recovery force and is very useful in ensuring good shape stability and complete recovery during the application of a device. ${ }^{64}$ The introduction of $10-15 \mathrm{wt} \%$ of nanofibers as a reinforcement phase into a low-modulus neat PMS imparts shape-memory properties with $R_{\mathrm{f}}$ close to $90 \%$ and $R_{\mathrm{r}}$ of $100 \%$ (after the first thermomechanical cycle) without deterioration over the rest of the cycles performed in these samples.

\subsection{Characterization of degraded samples}

3.3.1. Swelling studies. The swelling degree of the neat PMS, PMS/CNC and PMS/NF PLA nanocomposite samples was

b)

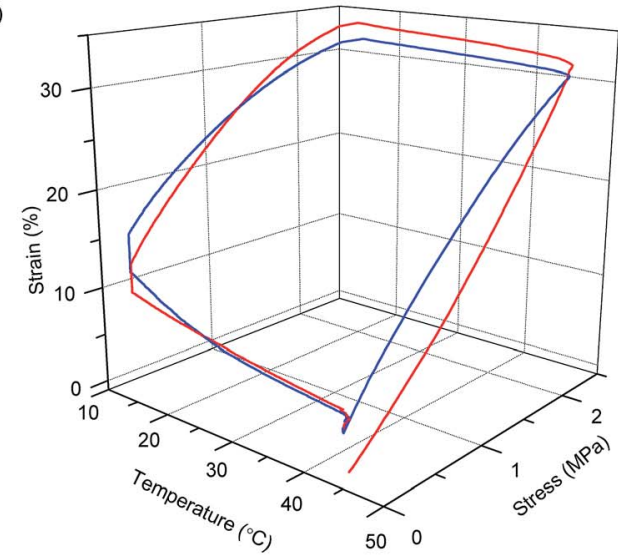

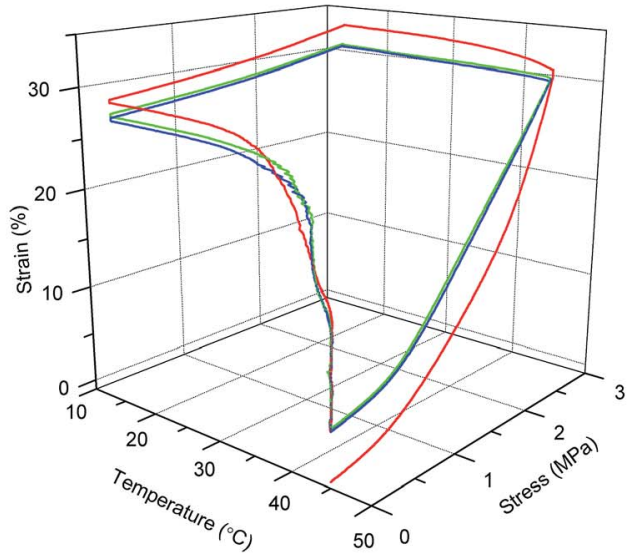

Fig. 4 Shape-memory stress-strain-temperature curves of two and three consecutive cycles for PMS/CNC 10 wt\% (a) and PMS/NF-PLA 10 wt\% nanocomposite (b) respectively. 

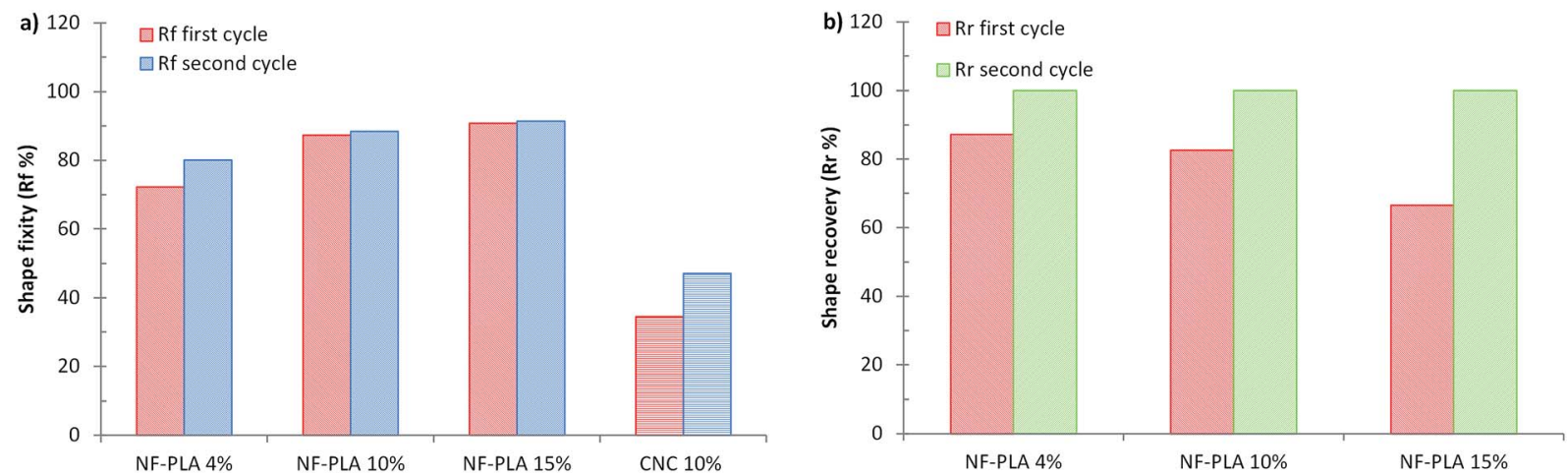

Fig. 5 Shape fixity characteristic values for the first and second cycles of PMS/NF-PLA nanocomposites compared with PMS/CNC 10 wt\% sample (a) and shape recovery characteristic values for the first and second cycles of PMS/NF-PLA nanocomposites (b).

determined after $24 \mathrm{~h}$ immersion in $\mathrm{SBF}$ at $37^{\circ} \mathrm{C}$, and the results are shown in Table 2. Regarding the PMS/CNC nanocomposites, there is a slight reduction in the swelling degree with increasing CNCs content, probably due to the higher crosslink density as a result of filler/matrix interactions. ${ }^{31,64}$ The trend of these results is in agreement with the mechanical properties' results. Neat PMS swells to $14.4 \pm 1.0 \%$ and to 10.4 $\pm 0.8 \%$ for $10 \mathrm{wt} \%$ of CNCs. Unlike in the case of PMS/CNC nanocomposites, the swelling results obtained for PMS/NFPLA nanocomposites seem to be related to the sample's wt $\%$ of NF-PLA, instead of to the reactions between the matrix and the filler. The initial swelling behavior of each component separately is $14.4 \pm 1.0 \%$ for neat PMS and $21.5 \pm 0.3 \%$ for NFPLA. However, by combining them to obtain nanocomposites, swelling is reduced as nanofiller content increases, with swelling of $12.4 \pm 1.1 \%, 6.3 \pm 1.1 \%$ and $5.4 \pm 1.3 \%$ for 4,10 and $15 \mathrm{wt} \%$ of NF-PLA, respectively. The high initial swelling of nanofiber mats could be attributed to the nanoporous structures and amorphous fraction presence. ${ }^{65-67}$ For a 4 wt\% PMS/ NF-PLA nanocomposite, the swelling degree of the isolated PLA-NF decreases significantly as voids in the interconnected network are filled with the PMS polymer matrix. Moreover, as was expected, by increasing the nanofiber weight fraction in the nanocomposite, the swelling degree lowers even further due to a combination of less porous inner structures combined and a PMS matrix that restricts nanofiber swelling. ${ }^{68}$

3.3.2. Degradation in SBF. The degradation of nanocomposites was investigated under physiological conditions (SBF, $37^{\circ} \mathrm{C}$ ) over periods of 150 and 210 days for PMS/CNC and PMS/NF-PLA nanocomposites, respectively. Fig. 6 shows neat PMS, PMS/CNC and PMS/NF-PLA nanocomposites degradation rates, revealing that the highest degradation rate corresponds to the neat matrix, which also has the highest swelling degree. At least for the first stages (14 to 42 incubation days), increasing nanofiber content seems to slow down the degradation rate (Fig. 6b). For these short degradation times, similar behavior is observed in the neat matrix and in the nanocomposite with 4 wt\% of NF-PLA, as the major part of each material is PMS.

Although the nanocomposites with 10 and $15 \mathrm{wt} \%$ of NF-PLA content show a slower degradation process, in accordance with swelling results, their behavior at short immersion times is closer to that of the neat matrix than to that of the neat nanofiber mat. Interestingly, the presence of different weight ratios of nanofibers does not seem to have a great influence on the degradation rate of the nanocomposites at longer degradation times, as the nanocomposite degradation trend becomes more equal over time. This is probably due to the degradation of the neat matrix, which makes it easier for the nanofibers to contact the SBF. As a result, degradation rates for all the PMS/NF-PLA nanocomposites at this stage are similar to the nanofibers mat's degradation profile.

As could be seen in Fig. 6 the mass loss of PMS/NF-PLA nanocomposites is comparable to that of $\mathrm{PMS} / \mathrm{CNC}$ nanocomposites at short immersion times, with mass loss for both systems near $15 \%$ after 56 days. However, at longer immersion times, the mass loss rate of PMS/NF-PLA nanocomposites is markedly lower than that of PMS/CNC nanocomposites. Thus, this degradation behavior observed in PMS/NF-PLA nanocomposites can be explained as a combination of the matrix presence, which protects the nanocomposites from water penetration, and the nanofibers' lower hydrolytic degradation rate due to their more hydrophobic nature. ${ }^{1,69,70}$ In summary, the degradation rate of PMS is reduced at long immersion times by the presence of PLA nanofibers. This fact, together with the diversity and stability of mechanical properties and enhanced shape-memory behavior of these nanofiber nanocomposites, could be beneficial in the development of active long-term implants for biomedical applications.

3.3.3. Mechanical properties of nanocomposites in SBF. In order to evaluate the effect of physiological conditions over the tensile properties of the developed materials, we allowed the samples to hydrate/degrade in SBF at $37{ }^{\circ} \mathrm{C}$ for 1,28 and 150 days and then subjected them to a micro-tensile test. The changes in Young's modulus over the degradation time for neat PMS, PMS/CNC and PMS/NF-PLA nanocomposites are shown in Fig. 7. Regarding the developed materials, it was observed that, in general, all the samples had low differences between dry and wet conditions, as similar Young's moduli were found in the dry state and after one day of hydration. As seen in Fig. 7a prolonged incubation time of up to 150 days produced a deterioration of mechanical properties for all PMS/CNC (Fig. 7a) and for PMS/NF-PLA nanocomposites with 4 to $10 \mathrm{wt} \%$ of NF-PLA 

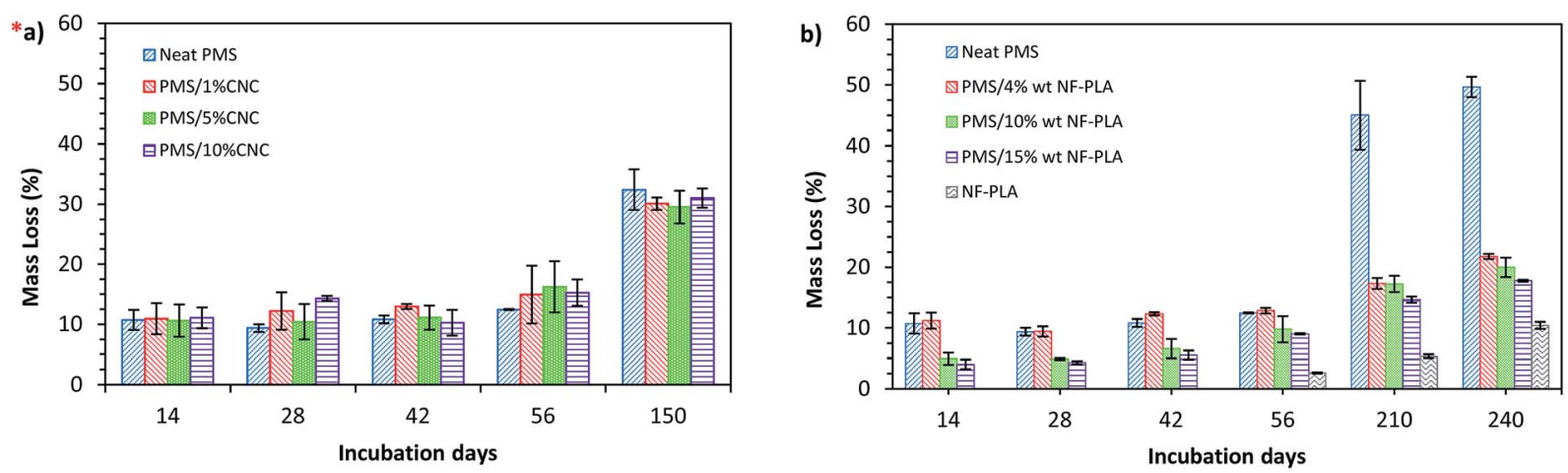

Fig. 6 Degradation of PMS/CNC nanocomposites (a) and PMS/NF-PLA nanocomposites (b) under physiological conditions (PBS at $37{ }^{\circ} \mathrm{C}$ ) monitored over immersion days. *(a), adapted from ref. 31.
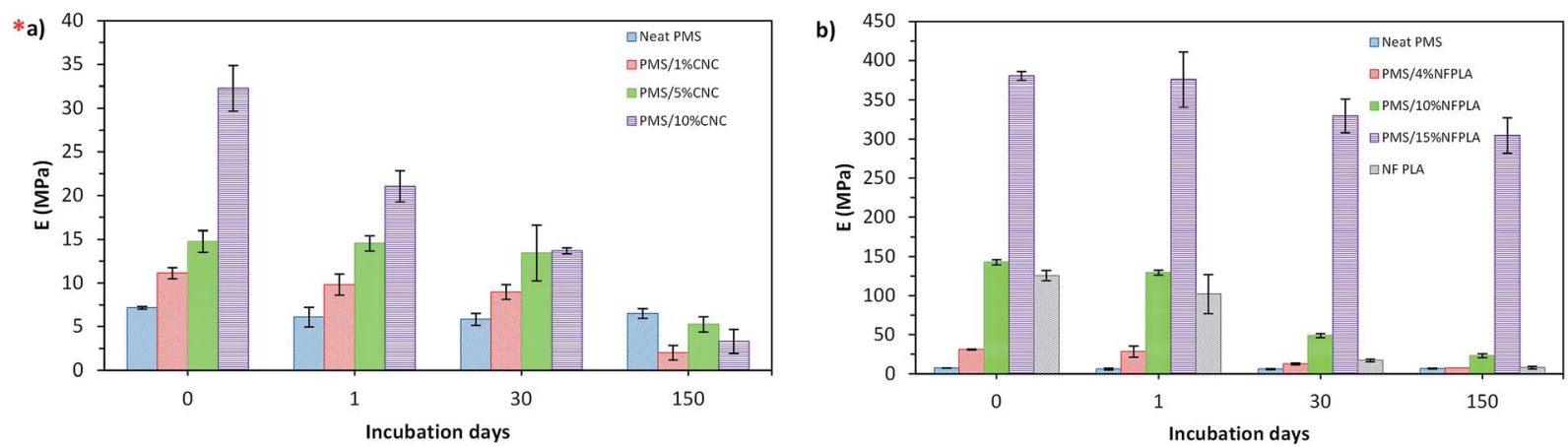

Fig. 7 Young's modulus values for the dry state (as prepared) and after 1, 30 and 150 days of immersion in PBS for neat PMS and PMS/CNC nanocomposites (a) and neat PMS, NF-PLA and PMS/NF-PLA nanocomposites (b). *(a), adapted from ref. 31.

content (Fig. 7b). However, the PMS/NF-PLA sample with 15 wt $\%$ of NF-PLA retained close to the $80 \%$ of its initial Young's modulus. It is also remarkable that the PMS/NF-PLA nanocomposites' mechanical behavior over immersion time seems much more predictable than that of the PMS/CNC nanocomposites. There is a clear trend in slower mass loss with increasing NF-PLA content that is not observed in their CNC counterparts.

Thus, main advantage of using nanofibers as PMS filler is that they provide high mechanical retention and stability that can be controlled by increasing the nanofibers' weight fraction. This high mechanical stability over an extended period of time makes these nanocomposites potential candidates to serve as mechanical support during tissue remodeling at a wound site. ${ }^{27,71}$ In addition, the use of nanofibers as a reinforcing material provides greater design flexibility, as one can separately modify the two functional components (matrix and fibers) to achieve optimum control of mechanical properties and degradation profiles.

Although it has been demonstrated that the easiest way to tune the properties of a PMS matrix is through combination with nanofibers, it should be pointed out that all developed PMS nanocomposites revealed mechanical properties that could be useful for a variety of medical applications, such as implantable medical devices, depending on the type of filler used. As an example, the mechanical properties of PMS/NF-PLA nanocomposites are comparable to those of human cartilage $(E=130 \mathrm{MPa}$, UTS; $19 \mathrm{MPa}$, elongation at break $=20-120 \%$ ) and skin $(E=15-50 \mathrm{MPa}$, UTS $=5-30 \mathrm{MPa}$, elongation at break $=35-115 \%) .{ }^{72}$ Other tough living tissues, such as tendon ( $E=143-2310 \mathrm{MPa})$, human ligament $(E=65-541 \mathrm{MPa})$, trabecular bone $(E=6.9-200 \mathrm{MPa})$ and cancellous bone ( $E=20-500 \mathrm{MPa}$ ) also a Young's moduli comparable to those of these samples. ${ }^{24,26,72,73}$ The mechanical properties obtained for $\mathrm{PMS} / \mathrm{CNC}$ nanocomposites are found in the range of several soft and elastic living tissues, such as veins, arteries and some articular cartilage. ${ }^{74-77}$ Finally, despite the fact that this work is indicative of biodegradability, to accurately represent the biodegradation and the usefulness of the developed materials as biomedical devices, future in vivo studies should be developed.

\section{Conclusions}

In this study, two different approaches to the reinforcing filler morphology were proposed to obtain polymer nanocomposites with potential biomedical applications, a PMS matrix is reinforced either with CNCs or electrospun PLA nanofibers. PMS pre-polymer was infiltrated into different amounts of NF-PLA followed by a thermal crosslinking procedure under vacuum to obtain PMS/NF-PLA nanocomposites. The mechanical, thermal, degradation and shape-memory properties of these 
materials were evaluated and compared with those of the PMS/ CNC system. Results indicated that by employing different nanofillers, a considerable wide range of mechanical and degradation properties are accessible. In this regard, the addition of NF-PLA in PMS matrices results in a remarkable improvement in mechanical properties, with a 53-fold increase in Young's modulus when a neat PMS matrix is combined with $15 \mathrm{wt} \%$ of PLA nanofibers, well above the enhancement obtained for the CNC-reinforced system. At the same time, this system offers the highest mechanical retention and stability over degradation time. At long degradation times, PMS/CNC samples retain Young's modulus on the order of the modulus for the neat PMS matrix (4-6 MPa). The same behavior occurs in PMS/NF-PLA nanocomposites with low wt\% of nanofibers $(4$ wt $\%)$; however, the addition of 10 or $15 \mathrm{wt} \%$ of NF-PLA allows for a Young's modulus of 25 and $300 \mathrm{MPa}$, respectively, a 3-fold and 46-fold increase over the values for the neat matrix and PMS/CNC nanocomposites. This mechanical behavior is directly related to the filler morphology, thus, a higher aspect ratio and contact area between the matrix and the reinforcing nanofibers results in effective load transference, even at long degradation times. In addition, the matrix probably protects the nanofibers from SBF penetration by lowering their hydrolytic degradation rate, which could help to the retention of these properties over time.

Regarding to shape-memory behavior, neat PMS and PMS/ CNC nanocomposite samples presented poor shape-memory properties; nevertheless, the introduction of nanofibers as filler improved the shape-memory properties of neat PMS thanks to the marked enhancement achieved in the rubbery modulus (more than 100 times higher than that of the neat PMS matrix with the addition of $15 \mathrm{wt} \%$ of NF-PLA). The resulting material can fix a temporary shape and obtain shape recovery values of $100 \%$ for the second thermomechanical cycle. In addition, the presence of two well-separated thermal transitions (as shown in DMTA analysis) enables the design of a tripleshape-memory systems for target applications. ${ }^{78}$ Thus, nanocomposites with good thermally activated shape-memory properties were obtained based on a PMS matrix reinforced with the NF-PLA with the best fixity ratios $\left(R_{\mathrm{f}}\right)$ and on filler contents of 10 and $15 \mathrm{wt} \%$. The data analysed and discussed for each nanocomposite system provide insights for broadening applications of the PMS matrix, independently on the type of filler used. On one hand, the addition of CNCs to a PMS matrix provides nanocomposites with a range of mechanical values in compliance with human elastic soft tissues, while the presence of NF-PLA induces similar properties to tough tissues. On the other hand, both systems offer highly desirable mechanical stability during incubation time, thus with the proper combination of matrix/amount of filler, reliable materials to be applied for mechanical support of damage tissues can be obtained. Finally, owing to shape-memory properties and the high retention of mechanical properties over degradation time during immersion in SBF, the obtained PMS/NF-PLA nanocomposites seem to be good candidates for use as smart and responsive materials in long-term medical applications.

\section{Acknowledgements}

The authors gratefully acknowledge financial support received from Spanish Ministry of Economy and Competitiveness (Project MAT2010/21494-C03), as well as the support of FPU grant from Spanish Ministry of Education, Culture and Sport (MED-FPU; AP2009-2482).

\section{References}

1 J. P. Bruggeman, B. J. de Bruin, C. J. Bettinger and R. Langer, Biomaterials, 2008, 29, 4726-4735.

2 Y. Li, G. A. Thouas and Q. Z. Chen, RSC Adv., 2012, 8229.

3 Y. D. Wang, G. A. Ameer, B. J. Sheppard and R. Langer, Nat. Biotechnol., 2002, 20, 602-606.

4 J. Yang, A. R. Webb and G. A. Ameer, Adv. Mater., 2004, 16, 511-516.

5 J. Yang, A. R. Webb, S. J. Pickerill, G. Hageman and G. A. Ameer, Biomaterials, 2006, 27, 1889-1898.

6 C. A. Sundback, J. Y. Shyu, Y. D. Wang, W. C. Faquin, R. S. Langer, J. P. Vacanti and T. A. Hadlock, Biomaterials, 2005, 26, 5454-5464.

7 J. B. Allen, S. Khan, K. A. Lapidos and G. A. Ameer, Stem Cells, 2010, 28, 318-328.

8 Z.-J. Sun, C. Chen, M.-Z. Sun, C.-H. Ai, X.-L. Lu, Y.-F. Zheng, B.-F. Yang and D. L. Dong, Biomaterials, 2009, 30, 5209-5214.

9 A. Mahdavi, L. Ferreira, C. Sundback, J. W. Nichol, E. P. Chan, D. J. D. Carter, C. J. Bettinger, S. Patanavanich, L. Chignozha, E. Ben-Joseph, A. Galakatos, H. Pryor, I. Pomerantseva, P. T. Masiakos, W. Faquin, A. Zumbuehl, S. Hong, J. Borenstein, J. Vacanti, R. Langer and J. M. Karp, Proc. Natl. Acad. Sci. U. S. A., 2008, 105, 2307-2312.

10 D. G. Barrett and M. N. Yousaf, Molecules, 2009, 14, 40224050.

11 Y. Kang, J. Yang, S. Khan, L. Anissian and G. A. Ameer, J. Biomed. Mater. Res., Part A, 2006, 77, 331-339.

12 A. K. Sharma, P. V Hota, D. J. Matoka, N. J. Fuller, D. Jandali, H. Thaker, G. A. Ameer and E. Y. Cheng, Biomaterials, 2010, 31, 6207-6217.

13 M. A. Hood, C. S. Gold, F. L. Beyer, J. M. Sands and C. Y. Li, Polymer, 2013, 54, 6510-6515.

14 X.-Q. Zhang, H. Tang, R. Hoshi, L. De Laporte, H. Qiu, X. Xu, L. D. Shea and G. A. Ameer, Biomaterials, 2009, 30, 26322641.

15 C. J. Bettinger, Macromol. Biosci., 2011, 11, 467-482.

16 T. Kiyotsukuri, M. Kanaboshi and N. Tsutsumi, Polym. Int., 1994, 33, 1-8.

17 T. Ding, Q. Liu, R. Shi, M. Tian, J. Yang and L. Zhang, Polym. Degrad. Stab., 2006, 91, 733-739.

18 G. C. Engelmayr, M. Cheng, C. J. Bettinger, J. T. Borenstein, R. Langer and L. E. Freed, Nat. Mater., 2008, 7, 1003-1010.

19 D. Motlagh, J. Yang, K. Y. Lui, A. R. Webb and G. A. Ameer, Biomaterials, 2006, 27, 4315-4324.

20 M. Nagata, T. Machida, W. Sakai and N. Tsutsumi, J. Polym. Sci., Part A: Polym. Chem., 1999, 37, 2005-2011.

21 C. J. Bettinger, B. Orrick, A. Misra, R. Langer and J. T. Borenstein, Biomaterials, 2006, 27, 2558-2565. 
22 V. R. Sastri, in Plastics in Medical Devices, Properties, Requirements and Applications, ed. V. R. Sastri, William Andrew Publishing, Boston, 2010, pp. 217-262.

23 Q. Z. Chen, A. Bismarck, U. Hansen, S. Junaid, M. Q. Tran, S. E. Harding, N. N. Ali and A. R. Boccaccini, Biomaterials, 2008, 29, 47-57.

24 S. L. Liang, W. D. Cook, G. A. Thouas and Q. Z. Chen, Biomaterials, 2010, 31, 8516-8529.

25 M. A. Meyers, P.-Y. Chen, A. Y.-M. Lin and Y. Seki, Prog. Mater. Sci., 2008, 53, 1-206.

26 K. Firoozbakhsh, I. S. Yi, M. S. Moneim and Y. Umada, Clin. Orthop. Relat. Res., 2002, 240-247.

27 Q.-Z. Chen, S.-L. Liang, J. Wang and G. P. Simon, J. Mech. Behav. Biomed. Mater., 2011, 4, 1805-1818.

28 Q. Liu, J. Wu, T. Tan, L. Zhang, D. Chen and W. Tian, Polym. Degrad. Stab., 2009, 94, 1427-1435.

29 Q. Chen, L. Jin, W. D. Cook, D. Mohn, E. L. Lagerqvist, D. A. Elliott, J. M. Haynes, N. Boyd, W. J. Stark, C. W. Pouton, E. G. Stanley and A. G. Elefanty, Soft Matter, 2010, 6, 4715-4726.

30 Á. Sonseca, S. Camarero-Espinosa, L. Peponi, C. Weder, E. J. Foster, J. M. Kenny and E. Giménez, J. Polym. Sci., Part A: Polym. Chem., 2014, 52, 3123-3133.

31 A. Sonseca, O. Sahuquillo, E. J. Foster and E. Giménez, RSC Adv., 2015, 5, 55879-55891.

32 J. S. Haghpanah, R. Tu, S. Da Silva, D. Yan, S. Mueller, C. Weder, E. J. Foster, I. Sacui, J. W. Gilman and J. K. Montclare, Biomacromolecules, 2013, 14, 4360-4367.

33 M. Jorfi, M. N. Roberts, E. J. Foster and C. Weder, ACS Appl. Mater. Interfaces, 2013, 5, 1517-1526.

34 A. Dufresne, Mater. Today, 2013, 16, 220-227.

35 A. Lendlein, A. M. Schmidt and R. Langer, Proc. Natl. Acad. Sci., India, Sect. A, 2001, 98, 842-847.

36 A. Lendlein and R. Langer, Sci. Technol. Adv. Mater., 2002, 296, 1673-1676.

37 W. Small, T. S. Wilson, W. J. Benett, J. M. Loge and D. J. Maitland, Opt. Express, 2005, 13, 8204-8213.

38 W. Small, M. F. Metzger, T. S. Wilson and D. J. Maitland, IEEE J. Sel. Top. Quantum Electron., 2005, 11, 892-901.

39 D. J. Maitland, M. F. Metzger, D. Schumann, A. Lee and T. S. Wilson, Lasers Surg. Med., 2002, 30, 1-11.

40 Y. Liu, K. Gall, M. L. Dunn and P. McCluskey, Acta Mater., 2004, 36, 929-940.

41 I. Chun and D. H. Reneker, Nanotechnology, 1996, 7, 216223.

42 A. Greiner, J. H. Wendorff, S. Ramakrishna and S. Agarwal, Electrospinning: Materials, Processing, and Applications, John Wiley \& Sons, Germany, 2012.

43 N. Bhardwaj and S. C. Kundu, Biotechnol. Adv., 2010, 28, 325347.

44 S. F. Fennessey and R. J. Farris, Polymer, 2004, 45, 42174225 .

45 I. S. Chronakis, J. Mater. Process. Technol., 2005, 167, 283293.

46 Z. M. Huang, Y. Z. Zhang, M. Kotaki and S. Ramakrishna, Compos. Sci. Technol., 2003, 63, 2223-2253.
47 X. Luo and P. T. Mather, Macromolecules, 2009, 42, 72517253.

48 X. Luo and P. T. Mather, Adv. Funct. Mater., 2010, 20, 26492656.

49 X. M. Dong, T. Kimura, J. F. Revol and D. G. Gray, Langmuir, 1996, 12, 2076-2082.

50 B. Braun and J. R. Dorgan, Biomacromolecules, 2009, 10, 334341.

51 A. Sonseca, L. Peponi, O. Sahuquillo, J. M. Kenny and E. Giménez, Polym. Degrad. Stab., 2012, 97, 2052-2059.

52 T. Kokubo, H. Kushitani, S. Sakka, T. Kitsugi and T. Yamamuro, J. Biomed. Mater. Res., 1990, 24, 721-734.

53 M. Behl and A. Lendlein, Mater. Today, 2007, 10, 20-28.

54 W. Wagermaier, K. Kratz, M. Heuchel and A. Lendlein, Adv. Polym. Sci., 2010, 226, 97-145.

55 D. Ratna and J. Karger-Kocsis, J. Mater. Sci., 2008, 43, 254269.

56 C. M. Yakacki and K. Gall, in Shape-Memory Polymers for Biomedical Applications, ed. A. lendlein, Springer-Verlag, Berlin, 2010, pp. 147-175.

57 S. Liang, W. D. Cook and Q. Chen, Polym. Int., 2012, 61, 1722.

58 K. Shanmuganathan, J. R. Capadona, S. J. Rowan and C. Weder, J. Mater. Chem., 2010, 20, 180-186.

59 Y. Li and J. A. Ragauskas, in Advances in diverse industrial applications of nanocomposites, ed. D. B. Reddy, InTech, 2011, pp. 18-36.

60 A. Pei, J. M. Malho, J. Ruokolainen, Q. Zhou and L. A. Berglund, Macromolecules, 2011, 44, 4422-4427.

61 A. Shirole, J. Sapkota, E. J. Foster and C. Weder, ACS Appl. Mater. Interfaces, 2016, 8, 6701-6708.

62 A. Saralegi, S. C. M. Fernandes, A. Alonso-Varona, T. Palomares, E. J. Foster, C. Weder, A. Eceiza and M. A. Corcuera, Biomacromolecules, 2013, 14, 4475-4482.

63 Q. Meng, J. Hu and Y. Zhu, J. Appl. Polym. Sci., 2007, 106, 837-848.

64 A. K. Gaharwar, A. Patel, A. Dolatshahi-Pirouz, H. Zhang, K. Rangarajan, G. Iviglia, S. R. Shin, M. A. Hussain and A. Khademhosseini, Biomater. Sci., 2015, 3, 46-58.

65 H. Ying Tang, D. Ishii, K. Sudesh, T. Yamaoka and T. Iwata, in Nanofibers, ed. A. Kumar, Intech, 2010, ch. 10.

66 W. J. Li, J. A. Cooper Jr, R. L. Mauck and R. S. Tuan, Acta Biomater., 2006, 2, 377-385.

67 K. Kim, Y. Akada, W. Kai, B. Kim and I. Kim, J. Biomater. Nanobiotechnol., 2011, 2, 353-360.

68 J. Choi, K. M. Lee, R. Wycisk, P. N. Pintauro and P. T. Mather, Macromolecules, 2008, 41, 4569-4572.

69 E. Hendrick and M. Frey, J. Eng. Fibers Fabr., 2014, 9, 153164.

70 D. P. Li, M. W. Frey and A. J. Baeumner, J. Membr. Sci., 2006, 279, 354-363.

71 T. Schepull, J. Kvist, C. Andersson and P. Aspenberg, $B M C$ Musculoskeletal Disord., 2007, 8, 116.

72 S. K. Ha, J. Biomed. Eng., 2006, 28, 534-541.

73 M. Sabir, X. Xu and L. Li, J. Mater. Sci., 2009, 44, 57135724. 
74 A. Thambyah, A. Nather and J. Goh, Osteoarthritis and Cartilage, 2006, 14, 580-588.

75 D. E. T. Shepherd and B. B. Seedhom, Rheumatology, 1999, 38, 124-132.
76 B. Amsden, Soft Matter, 2007, 3, 1335-1348.

77 J. M. Lee and D. R. Boughner, Circ. Res., 1985, 57, 475-481.

78 S. Chatani, C. Wang, M. Podgórski and C. N. Bowman, Macromolecules, 2014, 47, 4949-4954. 